\title{
Fatores determinantes para a continuidade da participação de idosos em programas de atividade física: a experiência dos participantes do projeto "Sem Fronteiras"
}

CDD. 20.ed. 613.7

796.018
Doralice Lange de SOUZA*

Rosecler VENDRUSCULO*
* Universidade Federal do Paraná.

\section{Resumo}

Este trabalho discute os resultados de uma pesquisa qualitativa, cujo objetivo foi o de investigar os fatores que determinam a participação continuada de idosos no projeto "Sem Fronteiras: Atividades Corporais para Adultos Maduros e Idosos", desenvolvido na Universidade Federal do Paraná. Participaram do estudo 10 idosos que estavam regularmente frequentando o projeto há pelo menos dois anos. Os dados foram coletados através de uma entrevista semi-estruturada. 0 guia de entrevista teve como linha condutora as seguintes questões: 0 que o (a) motivou a dar início à participação no projeto "Sem Fronteiras"? 0 que o (a) motiva a continuar participando do projeto? Quais as principais dificuldades que o senhor (a senhora) encontra para permanecer no mesmo? 0 que 0 (a) motiva a superar estas dificuldades? A análise das entrevistas teve como foco os principais temas que emergiram da fala dos participantes. Primeiramente foram analisados os dados de cada entrevista individualmente. A seguir, os dados foram cruzados buscando-se por temas comuns e divergentes entre as falas dos entrevistados. A principal conclusão da pesquisa foi que os idosos permanecem no programa não somente por perceberem benefícios à sua saúde física, mental e emocional, mas também pelas oportunidades que este Ihe oferece em termos de desenvolvimento pessoal, socialização, e troca de informações, experiências, suporte e afeto. As barreiras mais importantes encontradas pelos mesmos para dar continuidade à sua participação no projeto relacionam-se com problemas de saúde e compromissos familiares.

UnITERMOS: Idosos; Atividade física; Fatores de continuidade; Fatores de permanência.

\section{Introdução}

Estudos têm divulgado o significativo crescimento da população idosa. Segundo dados do InstituTO BRASILEIRO de Geografia E Estatística (2008), no período de 1997 a 2007, a população brasileira com 60 anos ou mais de idade teve um crescimento relativo de $47,8 \%$, sendo, hoje, em torno de $9 \%$. Também de acordo com o IBGE, enquanto que, em 1980, a expectativa de vida ao nascer era de 62,6 anos, em 2004, esta passou a ser em média 71,7 anos. Faz-se importante ressaltar que no Brasil, são consideradas idosas as pessoas com mais de 60 anos de idade (BRASIL, 1994, 2003). Já em países mais desenvolvidos com melhor qualidade de vida, são considerados idosos os indivíduos com mais de 65 anos (Mazo, Lopes \& BenedetTI, 2004).

$\mathrm{Na}$ medida em que a população idosa está aumentando, tem aumentado também a demanda para o desenvolvimento de políticas públicas, projetos e programas para atender as suas necessidades. Dentre estas necessidades, encontra-se a promoção da sua saúde. É neste sentido - o da promoção da saúde integral do idoso (física, mental e social) - que o nosso trabalho visa contribuir.

Várias pesquisas indicam uma correlação positiva entre a prática regular de atividade física $(\mathrm{AF})$ e a prevenção de fatores de riscos à saúde (BAUMAN, 2004; Kesaniemi, Danforth Junior, Jensen, Kopelman, Lefebvre \& ReEder, 2001; KoHL, 2001; Paffendarger \& Hyde, 1984; Paffenbarger, Hyde, Wing \& Hsieh, 1986; Pate, Pratt \& Blair, 1995; Powell, 1998). Muitos estudos também revelam os benefícios da atividade física especificamente para idosos (ex. American College of Sports Medicine, 
1998; Galper, Trivedi, Barlow, Dunn \& Kampert, 2006; Lee \& Paffenbarger, 2000; OKuma, 1998).

No caso de idosos, conforme aponta a Organização Mundial da Saúde (OMS), a AF promove os seguintes benefícios em termos fisiológicos: controle dos níveis de glicose; estimulação dos níveis de adrenalina e noradrenalina; fortalecimento muscular; melhoras no sistema cardiovascular e na flexibilidade; coordenação, equilíbrio, velocidade de movimentos e qualidade do sono. Em termos psicológicos e cognitivos, ela melhora o nível de relaxamento; reduz o estresse, ansiedade e estados depressivos; melhora o humor e o senso de bem estar; atrasa os declínios na velocidade de processamento e a reação do sistema nervoso central. Entre os benefícios sociais, quando praticada em grupos, promove um aumento da integração social e cultural do idoso e leva à formação de novas amizades e à expansão de redes sociais. Ao promover a manutenção e/ou melhorias das funções físicas e da independência do idoso, ela permite que o mesmo se sinta mais capaz de exercer papéis ativos na sociedade (World Health Organization, 1997).

Diversos fatores, como o nível sócio-econômico e educacional, situação de moradia, condições ambientais, aspectos nutricionais, acesso a atividades de lazer, entre outros, são responsáveis pela manutenção da saúde e da capacidade funcional dos indivíduos (CARVAlHo, 2001; Palma, 2001). No entanto, não se pode negar que a $\mathrm{AF}$ se constitui em elemento fundamental para a promoção da independência, auto-estima e habilidade do idoso de se relacionar com o mundo à sua volta e de garantir as suas condiçôes concretas de sobrevivência. Conforme apontam a OMS e autores como Deps (1993), Mazo, Lopes e BenedeTti (2004) e OKuma (1998, 2002), a boa funcionalidade física é essencial para que o indivíduo possa atingir seus objetivos, realizar tarefas diárias, cuidar de si mesmo, socializar, e se engajar em atividades sócio-educativas.

Embora vários estudos indiquem uma correlação positiva entre $\mathrm{AF}$ e saúde, grande parte da população não se engaja em $A F$ regular. Enquanto se sabe que a falta de adesão às práticas regulares e permanentes de atividade física é maior nas populaçôes de baixa renda e escolaridade (Brasil, 2007; Monteiro, Conde, Matsudo, Matsudo, Bonsenor \& Lotufo, 2003; NunOMura, 1998; PitAnga \& Lessa, 2005), se sabe também que o fator sócio-econômico por si só não consegue explicar o fenômeno do sedentarismo. Existe um alto grau de sedentarismo mesmo nas classes sociais mais abastadas e em países desenvolvidos onde as pessoas possuem mais acesso a informaçōes e recursos materiais para a prática de atividade física. Nos Estados Unidos, por exemplo, somente $30,8 \%$ dos adultos com 18 anos ou mais se engajam em atividade física em seu lazer. No caso de idosos entre 65 a 74 anos de idade, somente $24,7 \%$, e no caso daqueles acima de 75 anos, somente $17,9 \%$ se engajam neste tipo de atividade (Centers of Disease Control and Prevention, 2008).

Um estudo desenvolvido pelo Ministério da Saúde (BRASIL, 2007) em 26 capitais brasileiras com uma amostragem randômica de pessoas que vivem em residências que possuem telefone fixo concluiu que 27,8\% das mulheres e 30,9\% dos homens são fisicamente inativos. Esta situação é ainda mais grave no caso dos idosos. De acordo com esta mesma pesquisa, 53,7\% dos homens e 58,3\% das mulheres com mais de 60 anos são fisicamente inativos. Faz-se importante ressaltar que para esta pesquisa foram considerados fisicamente inativos aqueles que não praticaram nenhum tipo de atividade física em seu tempo de lazer nos últimos três meses, não fazem esforços físicos no trabalho, não vão para o trabalho a pé ou de bicicleta e não são responsáveis pela limpeza pesada de suas casas.

Considerando os níveis de sedentarismo entre idosos, e considerando que a AF regular é um dos elementos fundamentais para a promoção da saúde dos mesmos, apresentaremos alguns resultados de uma pesquisa qualitativa, cujo objetivo foi o de investigar os fatores que levam idosos a darem continuidade à sua participação em um projeto denominado "Sem Fronteiras: Atividades Corporais para Adultos Maduros e Idosos", um programa de atividades físicas e sócio-culturais de cunho educativo e recreativo para idosos, desenvolvido no Departamento de Educação Física da Universidade Federal do Paraná. Os resultados que serão apresentados a seguir podem servir tanto como base para futuros estudos na área, quanto também como recurso para o aprimoramento e/ou desenvolvimento de políticas, programas e projetos que não somente tornem possível a adesão, mas também a permanência de idosos em programas e projetos que envolvem atividade física (AF). 


\section{Metodologia da pesquisa}

A pesquisa teve como problema as seguintes questôes: Quais os principais fatores para a continuidade da participação de alguns idosos no projeto "Sem Fronteiras"? Quais as principais barreiras que os mesmos encontram para continuar participando do projeto? Optamos por estudar fatores de permanência em um programa de $\mathrm{AF}$ e não simplesmente fatores de adesão a este tipo de atividade, uma vez que sabemos que enquanto muitos iniciam práticas de AF, o índice de desistência de tais práticas é significativo (Dishman, 1988, 2001). Desenvolvemos um estudo qualitativo, uma vez que queríamos investigar em profundidade, e a partir do ponto de vista dos próprios idosos, o que os mantém engajados em um programa de AF.

Participaram do estudo 10 idosos que estavam regularmente frequentando o projeto há pelo menos dois anos. Os dados foram coletados através de uma entrevista semi-estruturada com questóes abertas. $\mathrm{O}$ guia de entrevista buscou contemplar, em um primeiro momento, dados sobre o perfil sócio-econômico e educacional dos participantes. A seguir, o guia teve como linha condutora as seguintes perguntas: $\mathrm{O}$ que o (a) motivou a dar início à participação no projeto "Sem Fronteiras"? O que o (a) motiva a continuar participando do projeto? Quais as principais dificuldades que o senhor (a senhora) encontra para continuar participando do mesmo? O que o (a) motiva a superar estas dificuldades? Na medida em que os participantes responderam estas perguntas, levantamos outras questôes com o objetivo de aprofundar as suas respostas e melhor apreender os seus pontos de vista.

\section{Resultados e discussão}

\section{O projeto Sem Fronteiras}

O Projeto "Sem Fronteiras" foi criado em 1999, e possui caráter educacional e recreacional. Ele tem por objetivos capacitar teórica e metodologicamente futuros profissionais para a atuação adequada na área do envelhecimento e da velhice; proporcionar aos idosos um espaço de atualização cultural, de integração inter e intra-gerações e de estímulo à auto-estima e ao autoconhecimento. O eixo norteador do trabalho é a manutenção da autonomia física e social do idoso. No nível social, o projeto visa mudanças culturais nas concepções negativas
A pesquisa foi aprovada pelo Comitê de Ética da Universidade Federal do Paraná (CEP/SD 697.032.09.05) e todos os participantes da pesquisa foram informados por escrito sobre os objetivos do estudo e assinaram um documento consentindo a sua participação no mesmo. As entrevistas foram desenvolvidas individualmente e em local e horário de maior conveniência para os participantes e duraram entre uma e duas horas. Elas foram todas gravadas e transcritas na íntegra, para garantirmos a qualidade dos dados para a análise.

O referencial teórico-metodológico utilizado para análise foi da pesquisa interpretativa (GEERTZ, 1989) e da "grounded theory" (teoria enraizada) (GLASER \& Strauss, 1967; Strauss \& Corbin, 1990). Desta forma, as categorias de análise surgiram dos próprios dados, de acordo com os principais temas que emergiram da fala dos participantes. Inicialmente analisamos os dados para cada um dos sujeitos da pesquisa. Em um segundo momento, fizemos uma análise cruzada dos dados de todos os participantes, buscando similaridades e diferenças entre os temas e categorias que emergiram de cada uma das entrevistas. Este procedimento levou ao desenvolvimento de novos temas e categorias de análise, que por sua vez, nos permitiram chegar aos resultados que apresentaremos a seguir. Durante o processo de pesquisa - entrevistas e análise de dados - procuramos por evidências que pudessem contrariar as nossas interpretações, até termos certeza que as mesmas eram o mais coerentes, consistentes e o mais próximas da realidade quanto possível (HAMMERSLEY \& ATKINSON, 1995; MaXwell, 1992; Miles \& Huberman, 1994).

vigentes sobre a velhice, uma vez que auxilia a população mais jovem rever sua visão sobre a velhice e possibilita aos idosos reavaliar sua experiência de envelhecimento e o seu papel na sociedade. A proposta compreende aulas de atividades corporais como ginásticas, caminhadas, jogos, esportes, danças, musculação, hidroginástica, entre outros. Estas atividades são alternadas com palestras e dinâmicas de grupo com o propósito de estimular o autoconhecimento, a auto-estima e a cultura geral. $\mathrm{Na}$ época em que coletamos os dados, 2006, as intervençōes aconteciam no Departamento de Educação Física (DEF) e no Centro de Educação Física e Desporto 
da Universidade Federal do Paraná, duas vezes por semana, no período das 14:00 às 17:00 horas. $O$ projeto era coordenado por uma professora do DEF e contava com a participação de 12 alunos do curso de educação física (estagiários) que desenvolviam o trabalho com os idosos.

Noventa e três idosos participavam do projeto. Deste total, 11 eram do sexo masculino, 82 do sexo feminino, e 82 aposentados. A faixa de idade estava situada entre 45 e 80 anos, sendo que 55 deles tinham entre 60 a 69 anos. O grau de escolaridade variava: 38 não possuiam o ensino fundamental completo, 21 completaram o ensino fundamental, mas não continuaram estudando, 23 concluíram o ensino médio e apenas 13 completaram seus estudos no nível. O seu salário médio era bem variado: 37 recebiam entre um e três salários mínimos, 20 recebiam entre cinco e oito salários mínimos e apenas seis deles recebiam mais do que oito salários mínimos. Após a nossa coleta de dados o projeto foi ampliado e hoje, julho de 2008, 160 idosos participam do mesmo. Ele é organizado em quatro turmas e cada qual atende as atividades duas vezes por semana. Uma professora do DEF continua coordenando o trabalho e 20 estagiários desenvolvem as atividades com os idosos.

\section{Facilitadores para a continuidade da participação dos idosos no projeto}

A maioria dos entrevistados alegou que iniciou a $\mathrm{AF}$ por razôes de saúde, motivo este também apontado por participantes de outros estudos (ANDREOTTI \& Okuma, 2003; Cardoso, Borges, Mazo, Benedetti \& Kuhnen, 2008; Freitas, Santiago, Viana, Leão \& Freyre, 2007; Rhodes, Martin, Taunton, Rhodes, Donnelly \& Elliot, 1999; SuZuKI, 2005). Somente uma participante, que havia dado início à $\mathrm{AF}$ quando ainda mais jovem, declarou motivos estéticos. Mas enquanto o fator de adesão à $\mathrm{AF}$ para a maioria deles foi a sua saúde no sentido biológico do termo, todos revelaram permanecer no projeto não somente por razōes físicas (diminuição de dores, melhora de disposição, prevenção de doenças), mas também por sentirem-se melhor em seus aspectos psicológicos e sociais. Vejamos, por exemplo, a seguinte fala:

Eu acho isso aqui maravilhoso. Para mim é uma análise! Eu chego terças e quintas aqui e brinco, converso, esqueço meus problemas, faço minha ginástica que todo mundo precisa [...]. É uma terapia que a gente faz aqui!

Durante os momentos que estão no projeto, os idosos tendem a esquecer-se de seus problemas cotidianos, o que em retorno, lhes proporciona um senso de leveza, bem estar e alegria.

Aquela hora que você ta aqui, você deixa tudo pra fora. Então você sai e pode começar tudo de novo. Você sai muito feliz. É uma beleza! [...] As vezes você vem preocupada, tem isso, tem aquilo pra fazer, tem alguma coisa que não ta dando certo. Eu ainda brinco com o meu marido, que os velhinhos adoram beijar. Ah, os velhos adoram chegar e te dar um beijo. Então a gente já entra rindo. Na hora que você tá fazendo exercício, sempre tem alguém que meche, que brinca, que fala alguma coisa. Então não tem como você sair dali, entende, não tem como tua cabeça sair dali. É muito bom!!!

O bem-estar gerado pela participação em programas de atividade física é citado como importante fator de manutenção da prática de atividade física também em outros estudos tais como FreITAS et al. (2007), ОкUма (1998) е SUZUKI (2005). Na verdade, para alguns dos idosos, o projeto Sem Fronteiras funciona enquanto uma terapia:

Eu estava entrando naquela das outras amigas de ficar socada dentro de casa, sem levantar e sem tirar o pijama [...] Se eu não tivesse feito isso, eu acho que hoje eu estava como a maioria das minhas amigas com depressão. [...]. [Aqui] você fala disso, do filho, do neto e o passeio que você fez [...] Você se anima né? [...]. Você começa a ter atividade de mente, porque se você fica sozinho dentro de casa, só pensa besteira.

Outro importante fator destacado pelos entrevistados para a sua continuidade no projeto foi a oportunidade de conhecer pessoas, de doar e receber o apoio de pares e de sentirem-se parte de um grupo:

A gente que está aqui, mas pelo duplo aspecto: da ginástica em si e da amizade [...] Tenho bastante amigos aqui. Quando a gente não os vê por uma semana, duas semanas, a gente já fica tudo preocupado, fica se ligando para casa para ver como é que está.

Todo mundo que faz ginástica, principalmente gente nova [...] quer desenvolver o peito, o pulmão, as costas, o pescoço, o braço [...]. Nos aqui não pensamos dessa forma [...] Simplesmente cumprimos aquele horário para estarmos juntos [...]. Não que essa ginástica aqui desenvolvida por eles vá trazer benefícios assim gritantes para o nosso físico e mente. Todo o exercício físico é bom para a nossa mente, mas o nosso corpo físico é difícil, estes exercícios são muito leves [...]. O beneficio que a gente tem é participar e se relacionar, tanto com o resto do pessoal, com os colegas ali, quanto com os professores né? 
Precisamos fazer uma ressalva em relação às palavras do participante acima. Estas não se aplicam à realidade dos outros entrevistados, quando ele afirma que as atividades do programa são leves e exercem pouca importância para a sua saúde física. Ele foi o único participante que menosprezou o papel da $\mathrm{AF}$ em sua saúde física e para a sua permanência no projeto. Todos os outros entrevistados comentaram que as atividades físicas desenvolvidas no projeto eram relevantes para a sua saúde e bem estar. A maioria deles alegou inclusive que a execução da AF do programa era "puxada" e exigia bastante esforço de sua parte. Da mesma forma que em nosso estudo, as pesquisas de Freitas et al. (2007), OKuma (1998) e SUZUKi (2005) também apontam as amizades e o senso de pertencimento a um grupo como fundamentais para motivar a participação de idosos em programas de atividade física. Para o idoso, a participação em grupos com pessoas da mesma geração através de vínculos de amizade é fundamental. Conforme expõe Deps (1993), as relações com parentes muitas vezes se baseiam em sentimentos de interesse e obrigação. Já as relações de amizade tomam como base a afeição e "consensos de valor". Assim, a possibilidade de constituir relações espontâneas e desinteressadas, onde são estabelecidos significados comuns entre pares, potencialmente promove o bem-estar emocional do idoso.

Tal como os participantes do estudo de FreITAS et al. (2007) е ОкUма (1998), os sujeitos de nossa pesquisa também destacaram o papel do professor em sua permanência no programa. $O$ relato desse sentimento segue, de forma geral, em consideraçôes do seguinte tipo:

Esse tratamento assim é muito gostoso pra gente,

é muito saudável. [...]. A gente percebe que eles

têm um cuidado com a gente [...] Eu não tinha

isso. Eu trabalhava e o negócio lá era chegar, por

a cara no serviço e não se tinha muito tempo de

fazer determinadas coisas, era trabalho mesmo.

A experiência do participante acima é comum a muitos que não possuem a oportunidade de desenvolver uma vida social ativa quando mais jovens, dado a compromissos profissionais e familiares. Na medida em que envelhecem, o senso de solidão destas pessoas tende a piorar, uma vez que tendem a se distanciar de seus colegas de trabalhos, perder familiares e amigos, e não raramente também enfrentam o desinteresse de entes queridos em relação às suas questões pessoais. Dessa forma, muitos facilmente se apegam a aqueles que preocupam com eles e que lhes oferecem atenção e carinho, como por exemplo, professores e colegas em um programa de atividade física.
Outro fator de permanência dos idosos no programa é a realização das atividades em um grupo da mesma faixa etária, o que os permite, conforme disse um dos idosos, se "sentir a vontade para ser eles mesmos". Diante de pessoas com necessidades e dificuldades similares, eles se sentem mais livres para se engajar - ou não - nas atividades, sem se sentir constrangidos por suas limitações. As seguintes passagens das entrevistas ilustram este ponto:

você se sente melhor com as pessoas da tua faixa etária [...]. Se você vai fazer um determinado tipo de exercício, entre nós, se você erra, se você não consegue, você as vezes até sai e senta, né? Os professores não vão: "Ah [fulana], tenta mais um pouquinho". E nem eu vou ficar constrangida. Na academia você já fica, porque claro que lá tem pessoas de todas as idades, então você não se sente tão a vontade!

Você fica muito, mais muito mais a vontade com a terceira idade, com um grupo todo mundo bichado, que cada um tem um probleminha, ou, a maioria. [...]. Você se sente melhor com as pessoas da tua faixa etária [...]. Porque, não sei. Eu acho que uma das coisas que pesa é isso: É que todo mundo tem as mesmas limitaçôes! (grifo nosso).

Antes de entrar no projeto duas participantes já haviam feito AF em academia. Segundo as mesmas, elas não se sentiam tão bem naquele tipo de ambiente quanto se sentiam no projeto. Uma explicação provável para isto talvez seja porque, nas academias e com pessoas mais jovens, além de fazerem atividades que não lhes pareciam adequadas, se deparavam constantemente com as suas limitaçôes. Já no projeto, com atividades próprias para a sua faixa etária e frente a um grupo onde todos possuem algum tipo de limitação, não precisam constantemente comparar-se com indivíduos "melhores" e "bater de frente" com suas dificuldades. Conforme disse uma das entrevistadas ao relatar a experiência de um baile à fantasia promovida pelo projeto durante uma excursão para a praia, outra vantagem de se desenvolver as atividades em grupos com pessoas da mesma faixa etária é que isto proporciona uma maior liberdade para se expressarem:

Imagine se eu tivesse numa excursão com pessoas de todas idades, se eu teria coragem de chegar lá e rebolar, rebolar mesmo [...]! É muito importante mesmo que as atividades sejam desenvolvidas em um grupo da terceira idade!

Faz-se interessante ressaltar que os aspectos relativos aos benefícios apontados pelos participantes do projeto em termos de socialização e de troca de experiências, 
de carinho, atenção e de apoio são consistentes com os resultados da pesquisa de OKUмA (1998).

As características lúdicas e recreativas do projeto foram também mencionadas enquanto um grande atrativo para a sua permanência no mesmo:

Tem aquelas brincadeiras que a gente brinca [...].

Eles fazem muito grupinho assim de festinha pra comemorar [...]. Agora nós fizemos um passeio pra praia. Foram dois dias assim maravilhosos. Ficamos seis velhas num quarto. Que delícia! Foi um sarro! Nós nos divertimos, teve baile, nós nos fantasiamos [...]. Ai meu Deus, que alegria! (grifo nosso).

Ao mesmo tempo que as características lúdicas e recreativas do Sem Fronteiras são atrativas para a maioria dos entrevistados, um participante de nossa pesquisa, no entanto, apresentou restriçōes em relação à algumas das atividades. Segundo ele, algumas delas são demasiadamente "infantis", como é o caso, por exemplo, de gincanas e atividades de "recorte e colagem". Como este participante gostava de todos os outros aspectos do projeto, e como estas atividades aconteciam apenas esporadicamente, ele se abstinha de participar nas mesmas quando estas aconteciam, sem se sentir desestimulado para manter a sua assiduidade no programa. Alguns trabalhos discutem a questão da "infantilização do idoso" (Alves Junior, 2004; Cachione, 2003; D’Ávila, 1999; Okuma, 1998). De acordo com os autores destes estudos, por falta de preparo, muitos profissionais tendem a perceber e a tratar os idosos como se estes fossem crianças e não tivessem características e demandas próprias. No caso de nossa pesquisa, conforme apontamos acima, apenas um dos participantes revelou perceber algumas das atividades do programa como "infantilizadas”. O problema da infantilização do idoso, no entanto, pode se apresentar de forma acentuada em vários âmbitos onde ocorre o trabalho com o mesmo.

Embora a maioria dos entrevistados tenha afirmado sentir dores físicas durante as atividades, todos alegaram que normalmente saiam melhor das atividades do que quando chegavam. As experiências vividas no projeto aparentemente os ajudavam a se sentir "mais vivos". Vejamos, por exemplo, a seguinte passagem de uma das entrevistas quando perguntamos a uma idosa como ela se sentia no final das aulas:

A gente sai, acho que não só eu, todas, saímos, descemos daqui, é uma criançada que dá gosto de ver! [...]. Então aquela meninada desce essa escada aqui [...] todas alegrinhas, porque todas que vem aqui gostam, todas sabe? A gente se sente mais vivo!

Outra razão alegada para a permanência no projeto foi que este estava lhes ajudando a "abrir a mente" e a relacionar-se melhor consigo próprios e com o mundo:

[Eu gosto] porque você se sente bem, se sente melhor com você mesma, você não agride outra pessoa, você é completamente outra pessoa. A gente se abraça [...] Precisa ver a alegria quando a gente se encontra [...] E pra mente da gente, pra saúde da gente, pra mente principalmente, porque você fica com a mente aberta!

O projeto "Sem Fronteiras" aparentemente oferecia aos participantes uma nova perspectiva para as suas vidas.

Ah eu gostei, eu gostei desde o começo e foi muito bom nossa! Aquilo pra mim sabe que, parece que eu nasci outra vez! [...] Sei lá porque, eu nem sei mais. Eu tinha mais disposição de trabalhar de sair, fazer mais amizades sabe... E assim uma outra vida.

Em síntese, e em consonância com o trabalho de ОкUмА (1998), a nossa análise nos leva a concluir que os entrevistados aderem ao projeto não somente pelo que ele contribui para a sua saúde física, mental e emocional, mas porque o mesmo lhes propicia convívio em grupo e uma rica troca de experiências, conhecimentos, afetos e suporte. Ele também lhes ajuda a descobrir novas possibilidades e significados para as suas vidas.

\section{Barreiras para a continuidade da participação no projeto}

Ao serem questionados sobre os maiores obstáculos para a sua permanência no projeto, os aspectos mais destacados pelos entrevistados foram os mesmos apontados por CARDOSO et al. (2008), Nascimento, Gobbi, Hirayama e Brazão (2008), RHODES et al. (1999) e SHEPPARD (1994): problemas de saúde. Dentre estes problemas, os mais enfatizados foram as "dores". Um dos entrevistados, por exemplo, ao ser indagado o que pensa ao realizar a AF respondeu: "Penso que não vejo a hora de acabar. Sofro muito. Tá chegando, tá acabando, ta acabando [...]. Quantas vezes faltam?” Ao perguntar-lhe o que o motivava a continuar no projeto apesar de suas dores, ele enfatizou o seu gosto pela vida e a sua esperança de melhorar o seu estado de saúde:

[Por] acreditar na vida, porque eu gosto de viver [...]. Eu acho que a gente teria que envelhecer com mais dignidade, quando você adoece (envelhece), você vai perdendo esse ânimo, você vai perdendo a coragem até de rir e de dar um sorriso. A dor não deixa, ela judia, ela cansa, mas que eu gosto de viver. Eu gosto! [...] Eu tenho esperança de que 
melhore um pouco. $\mathrm{E}$ as vezes melhora. Tem vezes que melhora, tem dias que determinadas dores até aliviam um pouco, mas aquela que é forte mesmo, essa não vai, essa fica ali marcando...

Mais adiante na entrevista, este entrevistado, tal como outros que participaram da pesquisa, revelou o quanto as relações afetivas com os professores e demais participantes do projeto, as brincadeiras e as trocas de experiências são fundamentais para a sua permanência no Sem Fronteiras:

Tenho artrose e [...] me dói muito [...] Saio daqui muito doído [...] Eu faço o exercício mais por garra, entende, dificuldade eu tenho até pra levantar um braço $[. .].[$ mas tem] muita coisa que a gente gosta, tem a amizade pelas pessoas que estão no projeto. A gente sente falta de conversar, dar uma risada, contar uma coisa, contar outra, cada um tem sua doença e fala como se fosse um troféu: A minha artrose, a minha pressão, a minha diabetes! Aquilo parece que é um troféu, e acabam dando risada. Eu [...] gosto de estar com o pessoal [...]. Esses jovens que nos aturam, são fantásticos! [...]. E você assim tem a obrigação de vir. (grifo nosso).

Outra barreira importante para a permanência dos idosos no projeto são os compromissos familiares, questão esta também levantada por RHODES et al. (1999) e SUZUKI (2005) a partir de seus estudos alguns participantes afirmaram que precisam cuidar de seus pais e/ou cônjuges acamados, o que dificulta a sua participação no projeto. A necessidade de cuidar de parentes adoentados - foi também apontada como uma importante barreira à manutenção da prática da AF pelas pesquisas de CARDOSO et al. (2008) e RHODES et al. (1999). Outro obstáculo para a permanência dos mesmos no Sem Fronteiras é que muitos ajudam seus filhos em tarefas cotidianas tais como a de pagar contas, levar e buscar objetos para conserto, levar e buscar netos na escola, etc. Vejamos, por exemplo, as seguintes passagens de entrevistas:

[...] e aí a filha liga: "Pai, você podia pagar uma conta pra mim?” Aí pego o papel vou ao banco pagar pra ela [...] Volto pra casa [...] Aí é claro leva comida pra ela que ta lá na escola. Aí leva o neto também pra escola. Aí eu fico com pena dela, digo me dê esse papel, vou pagar esse troço lá na imobiliária [...] E assim vai o tempo da gente!

Cada dia a gente tem uma coisa [...]. Tem as pessoas de casa né? [...]. Tem que ficar com o marido, tem neto né? As filhas trabalham, a avó tá "sem fazer nada" e sobra pra nós, né?
No caso de alguns idosos, a liberdade para cuidar de si próprios e de frequentar o projeto precisa ser conquistada, uma vez que tanto eles quanto familiares tendem a assumir que já que eles não trabalham fora, devem se colocar à disposição da família para a execução de tarefas cotidianas.

A falta de preparo das pessoas que trabalham no projeto pode também se constituir enquanto barreira para a participação dos idosos no mesmo. No caso de nosso estudo, todos os entrevistados, sem exceção, elogiaram os professores e o trabalho desenvolvido. Disseram que os professores (estagiários) eram extremamente carinhosos e dedicados e que as atividades propostas pelo projeto eram de uma forma geral, bastante significativa para eles. Fizeram, no entanto, algumas ressalvas referentes à falta de preparo de alguns dos "professores" (que na verdade eram estagiários) que fizeram intervenções no projeto. A história a seguir é longa, mas vale a pena ser contada com as próprias palavras de seu interlocutor, dado à riqueza da mesma:

Dois meninos novos que entraram recentemente deram uma bola fora, por inexperiência, por serem novos e não [...] conhecer a realidade e as atividades do projeto [...].Estava um sol quente de tarde e nós estávamos em uma sombra embaixo de uma árvore. Daí ele disse assim, "vamos lá na pista de atletismo". Daí fomos todos lá na pista de atletismo. Senti que o sol estava muito quente e fiquei na sombra de uma árvore que tinha perto. $\mathrm{O}$ pessoal foi lá e começaram a voltar. Já tinha ficado um amigo meu ali também. Daí mais uma senhora. Daqui a pouco mais outra, daqui a pouco mais um casal, e no fim ficou duas pessoas com ele lá. Aí ele ficou bravo e veio "Eu organizei uma atividade e quero fazer com vocês e me deixaram sozinhos, que vieram fazer aqui? [...] Vocês não querem fazer essa atividade? Então vocês não sabem o objetivo do projeto?" Aí ele olhou para mim: "E o senhor porque não foi lá?" Eu digo "eu não fui por um motivo muito obvio. Eu me recuso a ir naquele solão. O que eu vou fazer naquele sol? Para escutar umas bobagens de vocês e jogar uma bolinha lá? Você me desculpe mas eu não disse pra ninguém vir aqui onde eu estava. Eles vieram porque quiseram." Aí ele começou a falar. Aí eu disse: "espera um pouquinho aí, quanto tempo você está aqui no projeto?” E ele disse assim "ah faz três semanas". "Muito bem, eu faz três anos. Eu conheço o pessoal, vamos analisar assim, para nem você nem eu ficar bravo um com o outro. Veja bem, se o pessoal saiu de lá e vieram aqui na sombra é porque tem um motivo muito forte, alguma coisa está errada, o que você acha que está errada? Não 
é falta de consideração não. Aqui toda a vida, o pessoal aqui, eu inclusive, consideramos todos os professores que estão aqui. A gora veja bem, porque a gente chega lá para ficar com a cabeça nesse sol aí uma hora, sei lá quanto tempo vai durar essa sua aula? Eu não vou. Agora eu não disse pra ninguém vir aqui. Eu simplesmente não fui." Aí o pessoal disse, "pois é, tava muito quente o sol". "Ah não eu não vou dar mais aula" então uma coisa que a gente vê a capacidade da pessoa e a vivência da pessoa [...] Cada um sabe o seu limite [...].

O despreparo de pessoas que se propõem a trabalhar com idosos pode ser bastante problemático tanto no sentido de desmotivar os idosos a participar das atividades, quanto no sentido de causar danos à saúde dos mesmos. No caso do estagiário acima, além de o mesmo querer impor uma atividade sob o sol quente, falou com os idosos de forma desrespeitosa, insinuando que os mesmos não conheciam os objetivos do projeto, acusando-os de não serem participativos e ameaçando-os de não mais querer trabalhar com eles. Segundo o entrevistado citado acima, este jovem nem sequer tentou dialogar com o grupo para tentar entender o que estava acontecendo. A fala abaixo, feita por outro participante sobre a mesma situação também remete a esta questão:

Os professores são excelentes, mas chegaram dois novos que não entenderam a nossa jogada. Eles vieram com aquela responsabilidade de fazer a coisa acontecer [...] Vamos fazer isso! [...]. E nós gritando: "não, não dá, não dá!" Jogar bola no sol, prá nós não dá [...] A nossa pele já ta muito frágil também né? E você cansa mais! Nós estamos depois dos 60. [...] Eu simplesmente parei. Não falei nada e sentei. Aí vieram: "Como não vai?" "Não, não vou!" [...] São novos os dois professores, que vieram só naquele dia, e não aprenderam bem

\section{Considerações finais}

Projetos como o "Sem Fronteiras", ao mesmo tempo que envolvem a AF são também sócioeducativos e se constituem em importante investimento social. Além de promoverem a saúde física, mental, emocional e social dos idosos, estimulam novas aprendizagens e a formação de amizades e de grupos de apoio. Estas experiências, por sua vez, tendem a gerar novas dimensões/sentidos para a vida do idoso, aliviando assim processos de depressão e isolamento do mesmo. como funciona a coisa. Com idosos não é lidar com jovens e nem criança. Criança você manda né? Tem que fazer! Para nós não dá mais. Para nós é fazer aquilo que dá dentro das possibilidades só, mais nada né? (grifo nosso)

O trabalho com idosos precisa ser feito com cautela, tendo em vista as possibilidades, interesses e limitações dos mesmos. Nas falas acima, percebe-se que alguns participantes ofereceram resistência à prática autoritária e inapropriada do estagiário. Caso não tivesse havido resistência, a experiência com a AF poderia ter sido contra-indicada para muitos. Segundo os entrevistados, quando a coordenadora do projeto soube do problema, ela se mostrou bastante desapontada e buscou tomar providências junto aos estagiários no sentido de prevenir que o problema se repetisse. Gostaríamos de reforçar que, conforme sugeriu a entrevistada acima, os profissionais que se propóem a trabalhar com o idoso precisam ouvi-lo. O idoso quer - e precisa -ser respeitado até mesmo em sua decisão de não participar de certas atividades, caso sinta que as mesmas não sejam apropriadas para as suas condiçóes de saúde e disposição. A postura crítica dos participantes que mencionamos acima talvez seja uma consequência da própria proposta do projeto "Sem Fronteiras", que é a de promover a autonomia do idoso para a prática da atividade física. Conforme aponta D’Ávila (1999), os conhecimentos adquiridos em programas com a proposta de promover a autonomia dos idosos podem ajudar os mesmos a pensar a sua própria prática de atividade física de maneira mais crítica, criativa e independente. Estes novos conhecimentos podem beneficiar não só os idosos, mas também toda a sociedade que hoje está em um processo crescente de envelhecimento, desmistificando a visão de que o idoso é necessariamente passivo, frágil e dependente, e promovendo uma visão mais positiva da velhice.

Com base nos dados apresentados, podemos concluir que os participantes da pesquisa dão continuidade à sua participação no projeto não apenas pela sua contribuição para o seu bemestar físico, mas também para a sua socialização e troca de conhecimentos, suporte e afeto. Outros fatores que contribuem para a sua permanência no projeto são:

1) as características lúdicas e recreativas das atividades propostas; 
2) o fato das atividades serem desenvolvidas de acordo com as necessidades e interesses de sua faixa etária;

3) o fato de estarem entre pares, situação esta que lhes permite se sentir a vontade para fazer as atividades de acordo com as suas possibilidades e limitaçôes. As principais barreiras mencionadas pelos entrevistados para a sua permanência no projeto dizem respeito a problemas de saúde pessoais ou de familiares que precisam de cuidados e ou ajuda. Outra importante barreira se constitui em compromissos familiares. Isto, não obstantemente prejudica, quando não os impede completamente de participar em algumas sessões do projeto. Note que no caso de nossa pesquisa entrevistamos apenas pessoas que atendem o projeto com regularidade. Caso houvéssemos entrevistado pessoas que desistiram do projeto, provavelmente levantaríamos outros tipos de barreiras tais como distância do local das atividades, dificuldade de transporte, falta de segurança, falta de companhia para sair de casa, etc.

Tendo em vista o que discutimos até então, fazemos aqui algumas recomendações no sentido de contribuir para o desenvolvimento e implementação de políticas, projetos e programas de AF para idosos que visem não somente sua adesão, mas também a permanência dos mesmos em tais programas e projetos:

1) Criação de programas especificamente planejados para idosos, onde eles possam executar as atividades de acordo com as suas necessidades e possibilidades, sem constrangimentos;

2) Os programas devem proporcionar não somente práticas de $\mathrm{AF}$, mas também a educação, socialização e a troca de experiências entre os idosos, entre os mesmos e a comunidade próxima (ex. acadêmicos e professores de educação física);

3) As atividades devem possuir um caráter lúdico e recreativo, para que possam ser atrativas e manter o interesse dos participantes pelas mesmas;

4) Desenvolvimento de disciplinas e cursos especificamente planejados para a capacitação de profissionais para o trabalho com o idoso;

5) Implantação de programas educativos que promovam o direito do idoso de investir o seu tempo e energia em prol de sua própria saúde, educação e desenvolvimento pessoal. O idoso, por outro lado, precisa se permitir tomar melhor cuidado de si próprio, e quando necessário, aprender a dizer não às demandas impostas por outros, para que não negligenciem as suas próprias necessidades;

6) Finalmente, mas não menos importante, torna-se necessário proporcionar condições concretas para que os idosos possam frequentar os projetos e programas: condições tais como segurança e transporte são fundamentais para que os mesmos possam sair de casa e se deslocar para o local das práticas.

\begin{abstract}
Adherence factors to physical activity programs for older adults: the experience of the participants of the "Without Borders" project

This paper discusses the results of a qualitative research project that had as a goal to investigate adherence factors to a physical activity program for older adults in Brazil named "Sem Fronteiras: Atividades Corporais Para Adultos Maduros e Idosos", which translated into English means "Without Borders: Physical Activities for Mature and Older Adults". The participants of the study were 10 older adults who had been in the project for at least two years. Data were collected through semi-structured in-depth interviews with open-ended questions. The leading interview questions were: What led you to start the program? What motivates you to continue attending the program? What are the main difficulties you find in continuing to attend the program? What motivates you to overcome these difficulties? The coding categories emerged from the data. Initially, we analyzed the data for each of the research participants, raising and coding the main themes that emerged from their responses. Next, we did a cross-analysis of the data of all participants looking for similarities and differences between the themes. Our main finding was that the participants adhere to the project not only because of the benefits that they perceive in terms of their physical, mental and emotional health, but also because it offers them opportunities for their personal development, socialization, and exchange of experiences, information, support, and affection. The main barriers that the interviewees found to keep participating in the project were health problems and family commitments.
\end{abstract}

UNITERMs: Older adults; Physical activity; Adherence factors; Continuity factors. 


\section{Referências}

ALVES JÚNIOR, E.D. A pastoral do envelhecimento ativo. 2004. Tese (Doutorado em Educação Física) - Universidade Gama Filho, Rio de Janeiro, 2004.

AMERICAN COLLEGE OF SPORTS MEDICINE (ACSM). Position stand on exercise and physical activity for older adults. Medicine and Science in Sports Exercise, Madison, v.30, p.992-1008, 1998.

ANDREOTTI, M.C.; OKUMA, S.S. Perfil sócio- demográfico e de adesão inicial de idosos ingressantes em um programa de educação física. Revista Paulista de Educação Física, São Paulo, v.17, n.2, p.142-53, 2003.

BAUMAN, A.E. Updating the evidence that physical activity is good for health: an epidemiological review 2000-2003. Journal of Science and Medicine in Sport, Belconen, v.7, n.1, p.6-19, 2004. Supplement.

BRASIL. Lei n ${ }^{\circ}$ 8842, de 04 de janeiro de 1994. Dispõe sobre a política nacional do idoso, cria o Conselho Nacional do Idoso e dá outras providências. Diário Oficial da União, Brasília, 05 jan. 1994.

BRASIL. Lei n 10741, de 01 de outubro de 2003. Dispóe sobre o Estatuto do Idoso e dá outras providências. Diário Oficial da União, Brasília, 03 out. 2003.

BRASIL. Ministério da Saúde. Vigitel Brasil 2007: vigilância de fatores de risco e proteção para doenças crônicas por inquérito telefônico. Brasília, 2008. Disponível em: <http://portal.saude.gov.br/portal/arquivos/pdf/vigitel2007_final_web. pdf>. Acesso em: 14 maio 2008.

CACHIONI, M. Quem educa os idosos? Um estudo sobre professores de universidades da terceira idade. Campinas: Alínea, 2003.

CARDOSO, A.S.; BORGES, L.J.; MAZO, G.; BENEDETTI; T.B.; KUHNEN, A.P. Fatores influentes na desistência de idosos em um programa de exercício físico. Movimento, Porto Alegre, v.14, n.1, p. 225-39, 2008. Disponível em: <http:// www.cefid.udesc.br/laboratorios/gerontologia/documentos/artiogo-2.pdf>. Acesso em: 23 fev. 2009.

CARVALHO, Y.M. Atividade física e saúde: onde está e quem é o "sujeito" da relação? Revista Brasileira de Ciências do Esporte, Campinas, v.22, n.2, p.9-22, 2001.

CENTERS FOR DISEASE CONTROL AND PREVENTION. Early release of selected estimates based on data from the National HealthInterview Survey. 2008. Disponível em: <http://www.cdc.gov/nchs/about/major/nhis/released200806.htm\#7>. Acesso em: 14 set. 2008.

D’ÁVILA, F. Ginástica, dança e desporto para a terceira idade. Brasília: SESI/DN/INDESP, 1999.

DEPS, V.L. Atividade e bem-estar psicológico na maturidade. In.: NÉRI, A.L.(Org.). Qualidade de vida e idade madura. Campinas: Papirus, 1993. p.57-82.

DISHMAN, R.K. The problem of exercise adherence: fighting sloth in nations with market economies. Quest, Champaign, v.53, p.279-94, 2001.

(Ed.). Exercise adherence: its impact on public health. Champaing: Human Kinetics, 1988.

FREITAS, C.M.S.M.; SANTIAGO, M.S.; VIANA, A.T.; LEĀO, A.C.; FREYRE, C. Aspectos motivacionais que influenciam a adesão e manutenção de idosos a programas de exercícios físicos. Revista Brasileira de Cineantropometria \& Desempenho Humano, Florianópolis, v.9, n.1, p.92-100, 2007.

GALPER, G.I.; TRIVEDI, M.A.; BARLOW, C.E.; DUNN, A.; KAMPERT, J.B. Inversal association between physical inactivity and mental health in men and women. Medicine and Science inSports and Exercise, Madison, v.38, p.173-8, 2006. GEERTZ, C. A interpretação das culturas. Rio de Janeiro: LTC, 1989.

GLASER, B.G.; STRAUSS, A. L. The discovery of grounded theory: strategies for qualitative research. Chicago: Aldine, 1967. HAMMERSLEY, M.; ATKINSON, P. Ethnography: principles in practice. 2nd. ed. London: Routledge, 1995.

INSTITUTO BRASILEIRO DE GEOGRAFIA E ESTATISTICA. Síntese de indicadores sociais: uma análise das condiçōes de vida a população brasileira. Rio de Janeiro: 2008. Disponível em: <http://www.ibge.gov.br/home/estatistica/ populacao/condicaodevida/indicadoresminimos/sinteseindicsociais2008/indic_sociais2008.pdf>. Acesso em: 18 fev. 2009. KESANIEMI, Y.A.; DANFORTH JUNIOR, E.; JENSEN, M.D.; KOPELMAN, P.G.; LEFEBVRE; P.; REEDER, B.A. Dose-response issues concerning physical activity and health: an evidence-based symposium. Medicine and Science in Sports and Exercise, Madison, v.33, n.6, p.345-641, 2001.

KOHL, H.M. Physical activity and cardiovascular disease: evidence for a dose response. Medicine and Science in Sports and Exercise, Madison, v.22, p.472-83, 2001.

LEE, I.M.; PAFFENBARGER, R.S. Associations of light, moderate, and vigorous intensity physical activity with longevity. American Journal of Epidemiology, Baltimore, v.151, p.293-9, 2000.

MAXWELL, J. Understanding and validity in qualitative research. Harvard Educational Review, Cambridge, v. 62, p.279-300, 1992. 
MAZO, G.Z.; LOPES, M.A.; BENEDETTI, T.B. Atividade física e o idoso: concepção gerontológica. 2. ed. Porto Alegre: Sulina, 2004.

MILES, M.; HUBERMAN, A.M. Qualitative data analysis. 2nd. ed. Thousand Oaks: Sage, 1994.

MONTEIRO, C.A.; CONDE, W.L.; MATSUDO, S.M.; MATSUDO, V.R.; BONSENOR, I.M.; LOTUFO, P.A. Epidemiologia descriptiva de la actividad fisica en horas libres en el Brasil, 1996-1997. Revista Panamericana de Salud Publica, Washington, v.14, n.4, p.246-54, 2003.

NASCIMENTO, C.M.C.; GOBBI, S.; HIRAYAMA, M.S.; BRAZÃO, M.C. Nível de atividade física e as principais barreiras percebidas por idosos de Rio Claro. Revista da Educação Física/UEM, Maringá, v.19, n.1, p.109-18, 2008. Disponível em: <http://www.periodicos.uem.br/ojs/index.php/RevEducFis/article/viewFile/4321/2923>. Acesso em: 23 fev. 2009.

NUNOMURA, M. Motivos de adesão à atividade física em função das variáveis idades, sexo, grau de instrução e tempo de permanência. Revista Brasileira de Atividade Física e Saúde, Londrina, v.3, n.3, p.45-58, 1998.

OWEN, N.; BAUMAN, A. The descriptive epidemiology of physical inactivity in adult Australians. International Journal of Epidemiology, Baltimore, v.21, p.305-10, 1992.

OKUMA, S.S. O idoso e a atividade física. Campinas: Papirus, 1998.

. Um modelo pedagógico de ensino da educação física para pessoas com mais de 60 anos. In.: SEMINÁRIO INTERNACIONAL SOBRE ATIVIDADES FÍSICAS PARA A TERCEIRA IDADE, 5., 2002, São Paulo. Anais... São Paulo: Escola de Educação Física e Esporte/USP, 2002.

PAFFENBARGER, R.S.; HYDE, R.T. Exercise in prevention of coronary heart disease. Preventative Medicine, New York, v.13, p.3-22, 1984.

PAFFENBARGER, R.S.; HYDE, R.T.; WING, A.L.; HSIEH, C.C. Physical activity, all-cause mortality, and longevity of college alumni. New England Journal of Medicine, Waltman, v.314, p.605-13, 1986.

PALMA, A. Educação física, corpo e saúde: uma reflexão sobre outros “modos de olhar". Revista Brasileira de Ciências do Esporte, Campinas, v.22, n.2, p.23-40, 2001.

PATE, R.; PRATT, M.; BLAIR, S.N. Physical activity and public health: a recommendation from the centers for disease control and prevention and the American College of Sports Medicine. JAMA: The Journal of the American Medical Association, Chicago, v.273, n.5, p.402-7, 1995.

PITANGA, J.G.; LESSA, I. Prevalência e fatores associados ao sedentarismo no lazer em adultos. Cadernos de Saúde Pública, Rio de Janeiro, v.21, n.3, p.870-7, 2005.

POWELL, K.E. Habitual exercise and public health: an epidemiological view. In: DISHMAN, R.K. (Ed.). Exercise adherence: its impact on public health. Champaing: Human Kinetics, 1998.

RHODES, R.E.; MARTIN, A.L.; TAUNTON, J.E.; RHODES, E.C.; DONNELLY, M.; ELLIOT, J. Factors associated with exercise adherence among older adults: an individual perspective. Sports Medicine, Auckland, v.28, n.6, p.397-411, 1999. SCHOENBORN, C.A.; BARNES, P.M. Leisure-time physical activity among adults: United States 1997-1998. Hyattsvill: National Center for Health Statistics, 2002.

SHEPPARD, R.J. Determinants of exercise in people aged 65 years and older. In: DISHMAN, R.K. Advances in exercise adherence. Champaign: Human Kinetics, 1994.

STRAUSS, A.L.; CORBIN, J. Introduction to qualitative research: grounded theory procedures and techniques. Beverly Hills: Sage, 1990

SUZUKI, C.S. Aderência a atividade física em mulheres da universidade aberta á terceira idade. 2005. 104 f. Dissertação (Mestrado - Programa de pós-graduação em Enfermagem em Saúde Pública)- Escola de Enfermagem de Ribeirão Preto, Universidade de São Paulo, Ribeirão Preto, 2005.

WORLD HEALTH ORGANIZATION. The Heidelberg guidelines for promoting physical activity among older persons. Journal of Aging and Physical Activity, Champaign, v.5, n.1, p.2-8, 1997.

ENDEREÇO

Doralice Lange de Souza

R. Pe. Germano Mayer, 1284 - apto. 5 80040-170 - Curitiba - PR - BRASIL e-mail:dora@ufpr.br

Recebido para publicação: 30/04/2008

Revisado em: 03/07/2009

Aceito: 23/09/2009 